\title{
An Intervention Package to Support High School Students With Mental Retardation in General Education Classrooms
}

\author{
Susan R. Copeland and Carolyn Hughes \\ Vanderbilt University \\ Martin Agran \\ University of Northern Iowa \\ Michael L. Wehmeyer \\ University of Kansas \\ Stephanie E.Fowler \\ Vanderbilt University
}

Abstract

The effects of using a multicomponent intervention package to support the classroom performance of 4 high school students with mental retardation enrolled in general education classes were investigated. Intervention components were (a) modification of teacher-assigned worksheets, (b) instruction in assignment completion, (c) instruction in self-monitoring of classroom performance skills, (d) including students in setting performance goals, and (e) instruction in goal-evaluation. Implementation of the intervention package was associated with improved performance on modified assignments for all participants and higher report card grades for 3 participants. Three of 4 participants also correctly and independently evaluated their performance in relation to their performance goals. Findings are discussed and recommendations made for future research and practice.

The Individuals With Disabilities Education Act (IDEA) Amendments of 1997 state that students with disabilities should have access to the general education curriculum to the maximum extent possible. The Amendments also stipulate that modifications in the general curriculum must be provided to meet students' needs and ensure their success in the general education classroom. Such accommodations may not typically be available, however, particularly at the secondary level (HamreNietupski et al., 1999; Tralli, Colombo, Deshler, \& Schumaker, 1996). General education high school teachers characteristically expect students to independently perform basic skills, such as coming to class on time, following directions, finding information in textbooks, and completing assignments (Monda-Amaya, Dieker, \& Reed, 1998). Therefore, teachers may not believe that special supports are necessary, or they may question their own skills and knowledge in providing support to the increasing number of special education students served in general education classes (deBettencourt, 1999).

Although programs have been implemented that promote social inclusion of students with mental retardation in general education classrooms (e.g., Hunt, Alwell, Goetz, \& Sailor, 1990), less emphasis has been placed on developing strategies that teachers can use to support these students in meeting the academic or academic-related 
expectations of the general education class (deBettencourt, 1999; Monda-Amaya et al., 1998). For example, teachers could learn to support students in acquiring basic classroom performance skills, such as bringing materials to class, that are critical to success in general education environments (Monda-Amaya et al., 1998). DeBettencourt and Allen (1999) described a program designed to train secondary teachers to provide curricular modifications to support students with learning disabilities in accomplishing classroom performance skills and study behaviors, such as taking notes and organizing study time. Teacher training and research efforts to promote students' classroom performance skills, however, primarily have targeted students with limited support needs, such as students with learning disabilities (Polloway, Patton, Smith, \& Buck, 1997).

Five strategies, in particular, are recommended in the literature for supporting secondary students with more extensive needs in acquiring classroom performance skills (e.g., deBettencourt \& Allen, 1999; Farlow, 1996; Trammel, Schloss, \& Alper, 1994). These strategies are (a) modifying classroom assignments, (b) teaching assignment completion, (c) teaching self-monitoring, (d) including students in goal setting, and (e) teaching goal evaluation.

First, written classroom assignments, such as worksheets, can be modified by simplifying their content, decreasing the number of required responses, or embedding written prompts to guide students' performance (Janney \& Snell, 2000). For example, Farlow (1996) described modifications of mathematics assignments that included having students with disabilities complete one to two simple logic problems while their general education classmates completed 10 or more complex problems. Vallecorsa and deBettencourt (1997) used visual cues to direct students to perform story-writing tasks.

Second, direct instruction can be used to teach students skills needed to complete written assignments, such as sequencing tasks, organizing materials, or using texts to locate information. For example, MacArthur, Schwartz, Graham, Molloy, and Harris (1996) used direct instruction, modeling, and guided practice to teach students to write reports (e.g., selecting topics, organizing ideas, gathering information). DeBettencourt and Allen (1999) taught students to use organizational features of textbooks, such as boldface headings, while reading, recalling, and paraphrasing text book
Information.

Third, students can learn to use self-monitoring strategies to improve their classroom performance. Students can be taught to observe and record when they have performed targeted behaviors, such as bringing required materials to class and beginning work on time (Wehmeyer, Agran, \& Hughes, 1998). For example, Trammel et al. (1994) taught students to record on a chart all assignments they had completed and turned in during their classes. Foley and Epstein (1993) taught students to use a self-monitoring form to record their performance of "school survival skills," such as attending class, being on time, and using an assignment book.

Fourth, students can participate in setting their own performance goals. Teachers can solicit students' input in developing long-term goals to be included in their Individualized Education Programs (IEPs) as well as short-term goals related to daily classroom performance (Wehmeyer et al., 1998). For example, German, Martin, Marshall, and Sale (2000) assisted students in selecting daily performance goals from their IEPs. The students then were taught to develop action plans to achieve their goals and to incorporate their goal action plans into their daily class schedules.

Fifth, students can learn to evaluate their progress toward goal achievement. Visual aids, such as graphs, checklists, or charts, can help students compare their daily performance to their preestablished targeted goals (Smith \& Nelson, 1997). For example, Snyder and Bambara (1997) taught students to evaluate their performance of "classroom survival skills," such as being in seat at the beginning of class and handing in homework on time. Students learned to use their checklists to count the number of skills they performed each day and to compare the total number of daily skills to a pre-established goal.

These five strategies show promise in promoting the success of students in the general education curriculum. No published study, however, has investigated the effects of combining these strategies to support the classroom performance of high school students with mental retardation. Therefore, we sought to introduce the strategies as an intervention package to improve the classroom performance skills of high school students with mental retardation in general education classes. Intervention components were (a) modification of teacher-assigned worksheets (e.g., Vallecorsa \& 
deBettencourt, 1997); (b) instruction in assignment completion (deBettencourt \& Allen, 1999); (c) instruction in self-monitoring of classroom performance skills (e.g., Trammel et al., 1994); (d) including students in setting performance goals (e.g., German et al., 2000), and (e) instruction in goal evaluation (e.g., Snyder \& Bambara, 1997). We also assessed the perceptions of participating students and their general education teacher regarding changes in students' classroom performance. This study contributes to the literature by extending previous work on investigation of classroom support strategies to a novel population: high school students with mental retardation in content-area classes.

\section{Method}

\section{Participants}

Participants were 4 students enrolled in special education classes for students with mental retardation located in a large urban high school. Selection criteria were (a) enrollment in a general education class chosen by the student and in which grade performance was below average, (b) an expressed desire to improve classroom performance, and (c) prebaseline observation in the general education class that indicated a failure to initiate or complete written assignments. For example, students did not (a) put their name on assignments, (b) answer questions on assignments completely or correctly, or (c) turn in completed assignments to the teacher. The 4 students meeting these criteria were enrolled in general education cosmetology classes.

Monisha, a 14-year-old African American young woman, was identified as having mental retardation and a speech and language impairment. During baseline, she failed to turn to the required pages in her textbook to complete her written assignments. Instead, she copied sentences at random from her textbook or thumbed through the book's pages. In addition, her teacher reported that Monisha often refused to turn in assignments when requested to do so. Prior to the beginning of the study, Monisha's grade in cosmetology was a D. Monisha stated that although she liked being in the cosmetology class and wanted to improve her performance, she did not feel a part of the class nor did she wish to take additional general education classes in the future.

Carlos was a 15-year-old African American young man who had mental retardation. Prebaseline observation of Carlos in his cosmetology classroom revealed that when asked to answer written questions in his text, Carlos could not find the appropriate section within a chapter. When given a worksheet to complete, he simply sat at his desk without speaking until his teacher or a general education peer provided assistance. Carlos' cosmetology grade prior to implementation of the study was a C-. When asked, Carlos stated that he would like to improve his grade in class and "learn to do assignments by myself."

Rhonda and Tamara were 17-year-old African American young women identified as having mental retardation. Rhonda rarely answered questions on written assignments correctly or completely or turned in completed work to the teacher. Although she appeared to be working on assigned tasks, observation revealed that typically she was copying sentences or definitions from her textbook at random. The cosmetology teacher stated that although Rhonda had excellent practical cosmetology skills (e.g., braiding hair and providing manicures), she had difficulty using the table of contents or index in her text to locate material relevant to written assignments. Rhonda's grade in cosmetology prior to the study was a C. Rhonda indicated that she found the written assignments difficult and did not feel that she was truly a part of the class. She also remarked that she was not making good grades and would like to improve her performance.

Tamara was identified as having a language impairment in addition to mental retardation. She did not appear to pay attention when her teacher gave verbal instructions for class assignments, and she typically paged through her textbook randomly when given worksheets to complete. As indicated by her teacher, Tamara failed to begin or complete written assignments without frequent reminders from the teacher or a classmate. When assistance was not available, Tamara typically sat at her desk, watching but not interacting with her general education peers. Her grade prior to implementation of the study was a D. Tamara reported that she enjoyed the class but would like to improve her grade. (Additional participant characteristics are found in Table 1.)

\section{Setting}

Training and generalization sessions took place in the cosmetology classroom or its adjoining hairdressing salon during the two class periods in which the participants were enrolled ( 2 participants 
Table 1. Participant Characteristics

\begin{tabular}{|c|c|c|c|c|}
\hline Student & $\begin{array}{c}\text { Diagnosis and IQ } \\
\text { assessment }\end{array}$ & $\begin{array}{l}\text { Adaptive behavior } \\
\text { assessment scores }\end{array}$ & $\begin{array}{l}\text { Speech/language } \\
\text { assessment score }\end{array}$ & $\begin{array}{c}\text { Medical/behavioral } \\
\text { history }\end{array}$ \\
\hline Monisha, 14, African & Mental retardation, & Composite $=77$ & $\angle 40^{\circ}$ & None reported \\
\hline American female & $\begin{array}{l}\text { speech/language im- } \\
\text { pairment, } 40^{\mathrm{d}}\end{array}$ & & $\begin{array}{l}\text { Expressive }=50^{c} \\
\text { Receptive }=50^{c} \\
\text { Articulation impairment }\end{array}$ & \\
\hline $\begin{array}{l}\text { Carlos, } 15 \text {, African } \\
\text { American male }\end{array}$ & Mental retardation, $70^{\mathrm{d}}$ & $\begin{array}{l}\text { Communication }=62 \\
\text { Daily Living Skills }=67 \\
\text { Socialization }=77 \\
\text { Composite }=66\end{array}$ & None reported & $\begin{array}{l}\text { Hospitalized after birth and } \\
\text { at } 1 \text { year, history of } \\
\text { de velopmental delays and } \\
\text { hyperactivity; history of } \\
\text { vision problems }\end{array}$ \\
\hline $\begin{array}{c}\text { Rhonda, 17, African } \\
\text { American female }\end{array}$ & Mental retardation, $68^{\mathrm{e}}$ & $\begin{array}{l}\text { Communication }=52 \\
\text { Daily Living Skills }=69 \\
\text { Socialization }=70 \\
\text { Composite }=58\end{array}$ & None reported & $\begin{array}{l}\text { Easily frustrated; argues } \\
\text { and cries easily; history of } \\
\text { poor school attendance }\end{array}$ \\
\hline $\begin{array}{c}\text { Tamara, 17, African } \\
\text { American female }\end{array}$ & $\begin{array}{l}\text { Mental retardation, } \\
\text { language impair- } \\
\text { ment, } 40^{\mathrm{d}}\end{array}$ & $\begin{array}{l}\text { Communication }=29 \\
\text { Daily Living Skills }=54 \\
\text { Socialization }=51 \\
\text { Composite }=41\end{array}$ & $\begin{array}{l}\text { Language age }=3 \\
\text { years, } 7.5 \text { months, }{ }^{\mathrm{f}} \\
\text { articulation impairment }\end{array}$ & $\begin{array}{l}\text { First talked at } 2.5 \text { years; } \\
\text { his tory of developmental } \\
\text { delays }\end{array}$ \\
\hline
\end{tabular}


per class period). The remaining students in each class ( $n=20$ to 25$)$ were general education students. Each day, the cosmetology teacher assigned students independent written seatwork, such as worksheets. At least once per week, students also practiced hair-care techniques on mannequins in the adjoining hairdressing salon. Students' grades were based on both their written and practical skill performance.

\section{Materials}

The materials used in this study were (a) the cosmetology textbook and its accompanying workbook, (b) modified worksheets, and (c) goalevaluation sheets.

Text. The cosmetology text was designed to provide instruction in basic cosmetology skills (e.g., hair, skin, and nail care) and to prepare students to pass the State Board of Cosmetology examination, which was required for employment as a cosmetologist. The text was divided into chapters, each covering a broad topic area (e.g., "Properties of the Hair and Scalp"). Each chapter was divided by headings and subheadings into smaller sections that focused on a specific subtopic, such as "Hair Shapes." At the end of each chapter were shortanswer review questions related to the main points covered in the chapter.

Modified worksheets. With input from the general education teacher, we developed modified worksheets based on textbook questions and workbook assignments, which consisted of fill-in the blank or multiple-choice questions. Worksheets were identical to those assigned to the rest of the class with the following exceptions. (a) The number of questions per worksheet was decreased to 5 for Monisha, Rhonda, and Tamara and to 10 for Carlos. (b) Written prompts were embedded within the worksheet to-guide students' task performance. Specifically, prompts were provided for students to (1) take their worksheets from their folders, (2) write their names on their worksheets, (3) answer all questions, and (4) put their worksheets back in their folders when completed. In addition, prompts (i.e., key words from chapter headings or subheadings) were printed above each question on the worksheets to guide students to sections in the text relevant to answering the questions (range $=4$ to 6 prompts per question). (c) A small box was printed next to each prompt, which students were taught to check after performing the prompted task. Total number of worksheet-completion tasks per worksheet varied, depending on the number of questions and corresponding prompts the worksheet contained (range $=24$ to 64 tasks).

Goal-evaluation sheets. We constructed goal evaluation sheets (Grossi \& Heward, 1998) daily for each participant on which the participant's score (i.e., percentage of correctly performed worksheet completion tasks) on the previous day's worksheet was written. To the right of this score, the numbers 0 to 100 (by 10s) were printed in a vertical column in ascending order. These numbers represented possible percentage scores that participants could earn on their worksheets. For each participant, a number in the column was marked to indicate that participant's percentage score chosen during goalsetting training (see section Goal-Setting). Below this column of numbers, two boxes were printed, one containing a Y (i.e., "Yes") and the other an $\mathrm{N}$ (i.e., "No"). Participants were taught to marl, a box to indicate whether they thought they had met their goal on the previous day's worksheet (see section on Goal Evaluation Training).

\section{Outcome Measures}

Three outcome measures were assessed. Worksheet completion tasks performed was defined as the participant correctly performing the tasks required to complete one worksheet (as determined by the number of prompts per worksheet). Tasks not performed (e.g., answer left blank) and tasks performed incorrectly (e.g., wrong answer written) were both scored as incorrect. Self-monitoring steps performed was defined as the participant placing a check in the designated box on the worksheet immediately after each prompted task on the worksheet was performed. Checking that a task had been completed when it was not or failing to place a check in a box after a task was completed were both scored as incorrect. Goal-evaluation steps performed was defined as participants completing the goal-evaluation steps to indicate whether their score on the previous day's worksheet met their performance goal (see Goal-Evaluation Training). Steps were measured as prompted or unprompted.

\section{Social Validation Measures}

Social validation measures were used to verify the importance of the intervention's goal, procedures, and outcomes. Prior to baseline, the participants' cosmetology teacher was asked a series of open-ended questions to verify the importance of the target 
behavior. She also was queried concerning her preand postintervention expectations of the participants, her perceptions of participants' attitudes toward involvement in a general education class, and her perceptions of their performance on classroom as signments.

Participants also were asked a series of both forcedchoice and open-ended questions to (a) determine their perceptions of their performance of the target behaviors before and after intervention, (b) assess their feelings about participating in a general education class, (c) determine what their goals for these classes were, and (d) determine whether they perceived that they had met their goals after intervention. In addition, after the study was completed, the cosmetology teacher and the participants were asked their perceptions of the procedures used in the study.

\section{Experimental Design and Conditions}

A multiple-baseline-across-participants design (Kazdin, 1982) was used to evaluate the effects of the intervention package on the participants' performance of classroom assignments. There were four experimental conditions: (a) baseline, (b) training, (c) GoalEvaluation 1, and (d) Goal-Evalation 2. Generalization data were collected daily across all conditions. Instruction in worksheet completion, self-monitoring, and goal-evaluation was conducted daily during the training condition only, prior to collecting generalization data.

Baseline. During all baseline sessions (and all other generalization sessions throughout the study), we handed a folder containing one modified worksheet to each participant. They were instructed during the initial baseline session to take out the worksheet, complete it, return it to the folder, and replace the folder on a table at the back of the room. No additional instruction and no corrective feedback or verbal praise were provided to participants during baseline or any other generalization session.

Training. Following baseline, the trainer (the first author) implemented the training package with Monisha, with training for the other participants following sequentially. Training was composed of (a) soliciting participants' input in setting a performance goal and (b) instruction in worksheet completion, selfmonitoring, and goal-evaluation. To minimize disruption, training took place either in the classroom or in the hair salon, in an area away from the rest of the students in the class. The number of training sessions per participant ranged from 7 to 11 $(M=9)$. Duration of sessions ranged from 3 to 34 minutes across participants $(M=14)$.

Goal-setting occurred once, during the initial training session with each participant. The trainer (a) presented a rationale for the intervention; (b) provided a definition and an example of a goal (e.g., "something you try to achieve, such as working to save money to buy a CD player"); (c) showed the participants a list of their scores earned on the modified worksheets during baseline; and (d) asked the participants' input in setting a performance goal (i.e., the letter grade, for example, a $B$ that they would like to make on each daily worksheet). Using the goal-evaluation sheet, the trainer then marked the percentage in the number column corresponding to the letter grade selected by participants (e.g., "90\%") to provide the participants a visual representation of their goals.

Worksheet completion training was introduced during the first session of training, after the participant selected a performance goal. Participants were taught to use the prompts embedded on the worksheets to (a) remove the worksheets from their folders, (b) write' their names on the worksheets, (c) use the corresponding keywords in chapter headings or subheadings in their text to locate the correct answers to the worksheet questions, (d) check to determine whether they had answered all questions, and (e) return the worksheets to their folders. Using direct instruction, modeling, guided practice, praise, and corrective feedback, the trainer taught participants to perform each worksheet completion step. For example, to answer a worksheet question, the trainer taught participants to (a) look at and point to the corresponding written prompt on the worksheet, (b) turn to the section of the text referred to by the prompt, (c) locate in the text the correct answer to the worksheet question, and (d) write the answer to the question in the answer blank.

Self-monitoring training was introduced simultaneously with worksheet completion instruction during the first training session. After participants performed each worksheet completion task, the trainer directed them to place a check in the box to the right of the corresponding written prompt. Finally, the trainer instructed participants to remember to perform the worksheet completion tasks and self-monitoring strategy whenever instructed to complete modified worksheets (e.g., during on-going generalization sessions). 
Goal-evaluation training was provided to each participant beginning with the second training session. First, the trainer reminded participants of their performance goals and that performing and selfmonitoring worksheet completion tasks would help them attain their goals. Using modeling and verbal prompts, the trainer then instructed participants to take the goal-evaluation sheet (see Materials section) out of their folder and perform two goalevaluation steps. These steps were to (a) circle the number in the number column that matched the percentage score written on the sheet that represented their performance, and (b) mark the symbol (i.e., $Y$ or $N$ ) in the box below the number column to indicate whether they had achieved their goal. Participants were told that they had met their goal if their daily score fell within or above the marked area in the column (i.e., percentage marked by trainer to represent participant's goal). If the score fell below the marked area, they were told they had not met their goal. Participants received verbal praise for correctly performing both goal-evaluation steps (i.e., matching the number and determining whether they had met their goal) and for meeting their goal. If participants failed to meet their goal, they were encouraged to "Try again today to meet your goal."

Because Tamara failed to complete all questions on her worksheet before the end of the class period, a small digital timer was introduced in both training and generalization beginning in Session 27. During generalization sessions, when Tamara picked up her folder, the timer was set for 25 minutes. She was instructed to put the timer on her desk and try to finish her worksheet before the timer went off.

Training (including corrective feedback and verbal praise) for worksheet completion, selfmonitoring, and goal evaluation was withdrawn completely across participants when training criteria were met. Two criteria were required for termination of training: (a) $90 \%$ occurrence of self-monitoring behaviors and $90 \%$ occurrence of worksheet completion tasks for three consecutive training sessions, and (b) $90 \%$ occurrence of self-monitoring behaviors and $90 \%$ occurrence of worksheet completion tasks for three consecutive generalization sessions. Monisha, Carlos, Rhonda, and Tamara met criteria for withdrawal of training during Sessions 15, 18,23 , and 31 , respectively.
Goal-Evaluation 1. During Goal-Evaluation 1, training sessions no longer were provided. Instead, participants evaluated their goal attainment on the previous day's worksheet at the beginning of each generalization session, before starting work on that day's worksheet. Trainer feedback was provided as follows. From a distance of $1.5 \mathrm{~m}$, the trainer watched the participant fill out the goal-evaluation sheet, providing verbal correction if needed (e.g., participants circled the wrong percentage in the number column) to ensure accurate goal-evaluation. The trainer left the classroom when the goalevaluation sheet was completed, before the participant began working on the daily worksheet. Therefore, no corrective feedback or verbal praise was provided for worksheet completion or selfmonitoring. GoalEvaluation 1 was terminated after participants correctly and independently performed the two targeted goal-evaluation steps for 5 consecutive generalization sessions. Number of sessions across participants ranged from 5 to 17 .

Goal-Evaluation 2. During Goal-Evaluation 2, the trainer withdrew her presence completely. Number of sessions in the goal evaluation condition ranged from 3 to 11 across 3 participants (1 participant did not meet criteria to move into this condition).

\section{Data-Collection. Procedures}

The first author and a graduate student in special education served both as observers during training and as raters of participants' completed worksheets during generalization sessions. Prior to data collection, both observers discussed the definitions of outcome measures and description of the observation and rating procedures. The observers then practiced (a) observation and recording procedures in the actual classroom setting and (b) rating completed worksheets. Observers were required to reach a criterion of $80 \%$ interobserver and interrater agreement for all outcome measures before collecting data. Direct observation of target behaviors was used across all training sessions. Permanent product recording was used to assess all outcome measures during all generalization sessions. After each generalization session, the first author or the graduate student scored each participant's goal-evaluation sheets and modified worksheets to determine the percentage of worksheet completion tasks, self-monitoring steps, and goalevaluation steps participants had correctly performed. 


\section{Interrater and Interobserver Agreement}

The point-by-point agreement method (Kazdin, 1982) was used to assess the percentage of agreement for measures of performance of target behaviors. Interrater agreement was measured on a minimum of $27 \%$ of modified worksheets completed in generalization sessions within each condition for each participant $(M=42 \%$ across participants). Overall interrater agreement means and ranges across generalization sessions were as follows: percentage of correctly performed worksheet completion tasks (98\%, range 93 to 100), percentage of self-monitoring steps performed $(99 \%$, range $=97$ to 100$)$, and number of goal-evaluation steps ( $95 \%$, range $=88$ to 100$)$.

Interobserver agreement was measured during a minimum of $25 \%$ of training sessions ( $M=33 \%$ across participants). Overall interobserver agreement means and ranges during training were as follows: percentage of correctly performed worksheet completion tasks $(95 \%$, range $=88$ to 99$)$, percentage of self-monitoring steps performed (97\%, range, 93 to $100)$, and number of goal-evaluation steps (100\%).

\section{Fidelity of Treatment}

Fidelity of treatment was assessed across $36 \%$ of participants' training sessions. Findings indicated that the trainer performed correctly a mean of $99 \%$ of training steps (range $=97 \%$ to $100 \%$ ).

\section{Results}

\section{Generalization Sessions}

Percentage of correctly performed worksheet completion tasks. Figures 1 and 2 (upper panels) show the percentage of worksheet completion tasks performed correctly by participants without trainer assistance, praise, or feedback during generalization sessions. During baseline, participants seldom performed tasks required to complete their worksheets. Implementation of the training package resulted in substantial increases in the percentage of worksheet completion tasks performed by participants. Specifically, Monisha and Carlos correctly performed worksheet completion tasks at or above $85 \%$ after 3 and 1 training sessions, respectively and maintained this high level of performance for the remainder of the study. Rhonda increased her performance to $88 \%$ after only 2 training sessions. Although she maintained a high performance level throughout both Goal-Evaluations 1 and 2, with worksheet completion task performance falling below $80 \%$ on only two occasions (Sessions 27 and 31 ), her performance was more variable than was that of either Monisha or Carlos. Tamara's performance on

(C) American Association on Mental Retardation

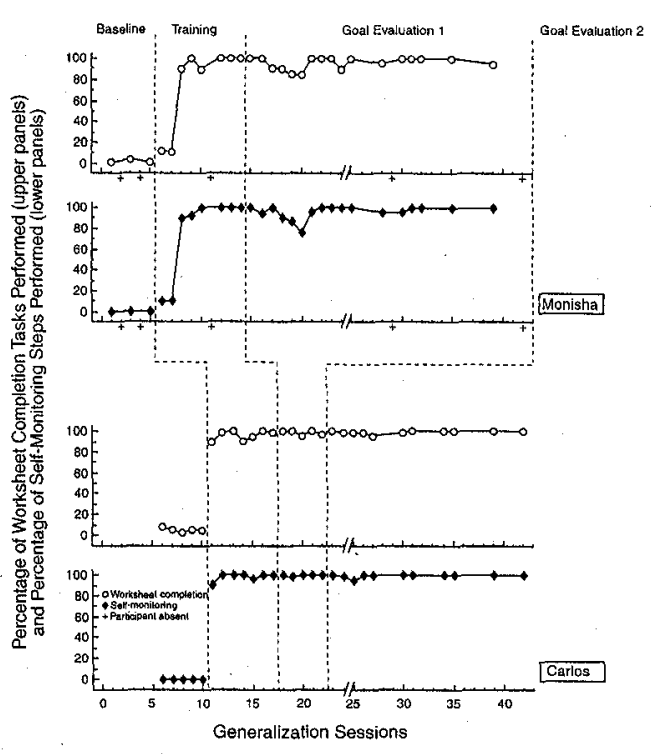

Figure 1. Percentage of worksheet completion tasks performed (upper panels) and self-monitoring steps (lower panels) performed by Monisha and Carlos during generalization sessions.

worksheet completion tasks increased to $73 \%$ immediately upon implementation of the training package. Analysis of her worksheets in GoalEvaluation 1 revealed

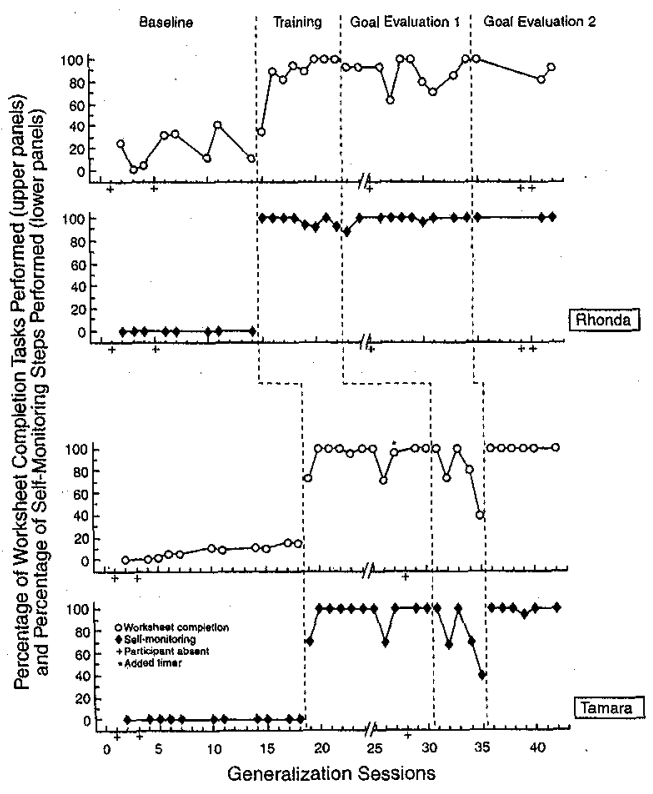

Figure 2. Percentage of worksheet completion tasks performed (upper panels) and self-monitoring steps (lower panels) performed by Rhonda and Tamara during generalization sessions. 
that she did not complete all items on the worksheet on three occasions in this condition, resulting in variable performance. However, after meeting criteria to move into Goal-Evaluation 2, her performance stabilized, maintaining at $100 \%$ for the last 6 consecutive sessions in the study.

Percentage of self-monitoring steps performed. The lower panels of Figures 1 and 2 show the percentage of self-monitoring steps performed by participants while accomplishing worksheet completion tasks. During baseline conditions, no participants self-monitored. After the introduction of self-monitoring training, all participants demonstrated immediate increases in the percentage of self-monitoring steps performed and maintained a high percentage of performance of self-monitoring steps across both maintenance conditions. Although Tamara's mean performance decreased slightly when she moved into the Coal-Evaluation 1 condition, her performance remained above $95 \%$ for the 6 consecutive sessions of the Goal-Evaluation 2 condition. The upper and lower panels of Figures 1 and 2 reveal a similar pattern of occurrence between self-monitoring steps performed and worksheet completion tasks performed for all participants, except Rhonda, throughout the study. Rhonda's performance of self-monitoring steps in the Goal-Evaluation 1 condition did not correspond as closely with her performance of worksheet completion tasks.

Number of goal-evaluation steps performed. As shown in Table 2, Carlos, Rhonda, and Tamara required few prompts to perform goal-evaluation steps accurately. Specifically, Carlos, Rhonda, and Tamara met criterion for complete fading of the trainer's presence and moved into the GoalEvaluation
2 condition after 5, 10, and 5 sessions, respectively (see Figures 1 and 2). During this condition, Tamara continued to accurately evaluate goal attainment for the remainder of the study (see Table 2). Rhonda made only two errors in evaluating goal attainment after moving into this condition, and Carlos made three errors. Although Monisha accurately evaluated goal attainment, she required trainer feedback to complete the goal-evaluation steps, and, thus, did mot meet criteria to move into Goal-Evaluation 2 (see Table 2).

\section{Social Validation}

Assessment of teacher's perceptions. Postintervention interviews with the cosmetology teacher revealed that she perceived positive outcomes for each participant, including positive changes in participants' completion of assignments, performance accuracy, self-confidence, and interaction with general education peers. For example, in speaking of Tamara, she said, "Before, she never completed anything, now she is able to complete them [the worksheets]. It makes her feel proud." In addition, she noted postintervention that Monisha appeared to feel more comfortable in the class (Le., enjoyed coming to class and felt a part of the class). She also reported satisfaction with the intervention's procedures, stating that "It helped me to break things down in order for the participants to understand."

Assessment of participants' goals and selfperceptions. During preintervention interviews, participants generally indicated a desire to improve their classroom performance and their grade in cos metology class. Postintervention, all participants

Table 2. Number of Unprompted, Prompted, and Incorrect Goal-Evaluation Steps Performed

\begin{tabular}{|c|c|c|c|c|c|}
\hline \multirow{3}{*}{ Particinant } & \multirow[t]{2}{*}{$\begin{array}{c}\text { Total no. of } \\
\text { oppor- } \\
\text { tunities } \\
\text { to perform } \\
\text { step }\end{array}$} & \multicolumn{2}{|l|}{ Step $1^{a}$} & Step $2^{b}$ & \multirow[b]{2}{*}{ Incorrect } \\
\hline & & Unprompted Prompted & Incorrect & Unprompted Prompted & \\
\hline & 23 & 16 & $-{ }_{--}^{\mathrm{d}}$ & 13 & $-{ }_{-}^{\mathrm{d}}$ \\
\hline Carlos & 20 & 19 & 1 & 17 & 2 \\
\hline Rhonda & 19 & 17 & 1 & 14 & 1 \\
\hline Tamara & 21 & 19 & 0 & 20 & 0 \\
\hline
\end{tabular}


indicated that they had accomplished their goals by learning the worksheet completion skills, selfmonitoring, and goal-evaluation strategies taught (see Table 3). In addition, they generally expressed their satisfaction with the skills they had learned. For example, Carlos indicated that he was now completing assignments independently, and Rhonda stated that she was making good grades in the class. Monisha, who had stated during preintervention interviews that she did not want to take any additional general education classes, also indicated that she now wanted to take other general education classes, such as a culinary arts class.

In general, participants' responses suggested they perceived that effort (i.e., performing the strategies) helped them meet their goals (see Table 3). All participants, with the exception of Rhonda, responded positively to the use of the goal-evaluation sheet. For example, Monisha stated, "It helped me see my grades." Rhonda, however, stated that the sheet "made me feel like I was coloring." Carlos and Monisha noted that the best thing about using the worksheets was being able to find answers to the questions.

Participants' overall worksheet performance and class grades. All participants showed substantial increases in overall mean performance of worksheet completion tasks after introduction of the training package as compared to baseline performance. Increases in means were as follows: Monisha (3\% to $86 \%$ ), Carlos ( $6 \%$ to $98 \%$ ), Rhonda (20\% to $87 \%$ ), and Tamara $(8 \%$ to $93 \%)$. Three of 4 participants' improved performance was corroborated by improvement in their cosmetology class grades, as reflected on their report cards pre- and postintervention. Monisha's grade in cosmetology increased from a $D$ to a $\mathrm{C}$; Rhonda's, from a $\mathrm{C}$ - to a $\mathrm{C}$; Tamara's from a $D$ to a $C$; Carlos' grade remained a C.

\section{Discussion}

In this study, a multicomponent intervention was effective at increasing worksheet completion tasks of four high school students with mental retardation in their general education classes. Intervention components were (a) modifying teacher assigned worksheets; (b) providing instruction in assignment completion, self-monitoring, and goal-evaluation; and $(c)$ including students in setting performance goals. The intervention was associated with higher report grades for 3 participants, and 3 of the 4 participants also correctly and independently evaluated their performance in relation to performance goals. These findings present a first step toward supporting the classroom performance of students with mental retardation in general education classes.

First, students in our study learned to perform teacher-expected classroom behaviors. All participants had been reported by their general education teacher as failing to complete assigned written class work. Students were expected to complete written assignments independently as a large proportion of their grade in class. However, prior to intervention, participants required assistance from their classroom teacher or peers to complete and turn in assignments. Even after modifications to the teacher-assigned worksheets were made in baseline (e.g., decreasing number of questions per assignment and embedding written prompts), participants' written performance was poor. Therefore, modifying worksheets alone was not effective in improving worksheet performance. After participating in selecting a performance goal and receiving instruction in worksheet completion, self monitoring, and goal-evaluation, however, students improved their performance on written assignments.

It may be that a combination of strategies is needed within general education settings to support students with mental retardation in improving their classroom performance. Simply modifying class assignments (e.g., embedded written cues) was not sufficient to improve students' classroom performance (Figures 1 and 2, baseline performance). Providing students who have mental retardation with more than one type of support (e.g., modified assignments, direct instruction, and self-monitoring) may be necessary for their successful participation in typical classroom tasks. This finding is important because high school teachers typically expect students to perform basic classroom-related skills independently (Monda-Amaya et al., 1998). If students with mental retardation can decrease their need for assistance in meeting classroom expectations, the attitudes of general education teachers toward their inclusion may be affected favorably.

Second, few investigations of general education classroom performance skills have included students with moderate to extensive support needs as participants. In addition, few researchers have involved students with mental retardation in setting goals related to their academic achievement 
Table 3. Students' Postintervention Self-Perceptions

\begin{tabular}{|c|c|c|c|c|}
\hline \multirow[b]{2}{*}{ Question } & \multicolumn{4}{|c|}{ Responses } \\
\hline & Monisha & Carlos & Rhonda & Tamara \\
\hline $\begin{array}{l}\text { 1. Did you like using the work- } \\
\text { sheets and strategies we } \\
\text { taught you? }\end{array}$ & $\begin{array}{l}\text { "The worksheets weren't } \\
\text { easy, but you liked } \\
\text { doing them. They were } \\
\text { not too long." }\end{array}$ & $\begin{array}{l}\text { "Yes. They helped me do } \\
\text { better with my work." }\end{array}$ & $\begin{array}{l}\text { "Yes, I like them because } \\
\text { it gave me something } \\
\text { to do. It got me ready } \\
\text { for my license." }\end{array}$ & $\begin{array}{l}\text { "Yes, they were fast. I } \\
\text { liked using the work } \\
\text { sheets and strategies." }\end{array}$ \\
\hline $\begin{array}{l}\text { 2. Are you finishing your } \\
\text { as signments now? }\end{array}$ & $\begin{array}{l}\text { "Yes, I am able to } \\
\text { complete my assignments." }\end{array}$ & "Yes." & "Yes." & "Yes." \\
\hline $\begin{array}{l}\text { 3. What was the best thing } \\
\text { about using the worksheets } \\
\text { and strategies? }\end{array}$ & $\begin{array}{l}\text { "Being able to find the } \\
\text { words." }\end{array}$ & $\begin{array}{l}\text { "It was easy to find the } \\
\text { chapters and the listings } \\
\text { of the names." }\end{array}$ & $\begin{array}{l}\text { "I can't really explain it. } \\
\text { But they helped me a } \\
\text { lot." }\end{array}$ & $\begin{array}{l}\text { "Yes, I liked them. Sheets } \\
\text { were easier than other } \\
\text { assignments." }\end{array}$ \\
\hline $\begin{array}{l}\text { 4. After you learned to use the } \\
\text { worksheets, did you meet } \\
\text { the goal you set for your- } \\
\text { self, to make a } \\
\text { worksheets in } \text { Ms.__ }_{\text {_. }} \text { 's class? }\end{array}$ & $\begin{array}{l}\text { "Yes, because I was able } \\
\text { to get my grades up. } \\
\text { Also, I made my mother } \\
\text { happy." }\end{array}$ & "Yes." & "Yes." & "Yes." \\
\hline $\begin{array}{c}\text { 5. Why do you think you met } \\
\text { your goal? Or why not? }\end{array}$ & $\begin{array}{l}\text { "I am now happy with my } \\
\text { grades." }\end{array}$ & "I tried." & $\begin{array}{l}\text { "I felt that I had to work } \\
\text { at it, and that's what I } \\
\text { did." }\end{array}$ & "Because I made 100s." \\
\hline $\begin{array}{l}\text { 6. Did you like using the goal- } \\
\text { evaluation sheet? Why or } \\
\text { why not? }\end{array}$ & $\begin{array}{l}\text { "Yes, because it showed } \\
\text { me my grades." }\end{array}$ & $\begin{array}{l}\text { "Yes, the work wasn't as } \\
\text { hard as, when Ifirst } \\
\text { started": It was appropri- } \\
\text { ate. It helped me better } \\
\text { than the work Ms. - } \\
\text { was giving me." }\end{array}$ & $\begin{array}{l}\text { "No, because it made me } \\
\text { feel like I was coloring." }\end{array}$ & $\begin{array}{l}\text { "Yes, but I don't know } \\
\text { why." }\end{array}$ \\
\hline $\begin{array}{l}\text { 7. Did using the goal-evalua- } \\
\text { tion sheet help you know } \\
\text { whether or not you had met } \\
\text { your goal, to make a__- on } \\
\text { the worksheets in Ms._-_ 's } \\
\text { class? }\end{array}$ & "Yes." & "Yes." & "Yes." & "Yes." \\
\hline $\begin{array}{l}\text { 8. Do you think using these } \\
\text { kinds of worksheets or strat- } \\
\text { egies would help you in any } \\
\text { other classes? How? }\end{array}$ & $\begin{array}{l}\text { "Yes, it helped me find } \\
\text { words." }\end{array}$ & $\begin{array}{l}\text { "Yes, it just depends. The } \\
\text { strategies could be } \\
\text { applied to other subjects." }\end{array}$ & $\begin{array}{l}\text { "Yes, I can do them } \\
\text { better and they are more } \\
\text { easier." }\end{array}$ & $\begin{array}{l}\text { "Yes, would help me to } \\
\text { go better." }\end{array}$ \\
\hline
\end{tabular}


or taught students to evaluate their progress toward goal achievement. Unlike previous investigations of goal setting (e.g., Kokubun, 1999), this study took place within a general education classroom and targeted skills identified as important by participants' parents and their general education teacher. In addition, providing appropriate supports for students in this study allowed them to complete assignments similar to those of their general education classmates. Participants used the same text as did their general education peers, and their worksheet questions covered the same topics. As researchers, practitioners, and parents continue to debate whether critical academic and daily living skills can effectively be taught to students with mental retardation within general education settings or whether students are better served in separate classroom environments, these findings add to existing research suggesting that with appropriate instruction and support, students with mental retardation can acquire expected classroom performance skills within general education classrooms (McDonnell, 1998).

Third, general education teachers report that they need more knowledge and skills to include and support students with disabilities in general education curricula and classes (Wehmeyer et al., 1998). We investigated the effects of a multicomponent package (i.e., modifying written assignments; teaching worksheet completion; selfmonitoring and goal-evaluation; including students in setting performance goals) to support students in performing expected classroom behaviors. Although it is not known which component(s) of the intervention package may have been responsible for students' imp roved performance, all of the strategies introduced could be adapted by general education teachers to support students with disabilities who are included in their classes. For example, as we did, teachers could provide students with written prompts to initiate and complete assignments as well as encourage students to monitor their progress toward achieving performance goals.

Limitations of the study suggest areas for future research and practice. First, reported changes in participants' behavior represent only a first step in shaping classroom performance skills. Target behaviors taught (e.g., writing name on worksheet, using organizational text features to locate information, checking to determine whether all questions were answered) would be considered elementary by typical high school standards. How ever, prior to training, participants rarely were completing written assignments in their general education classes and simply paged through their textbooks at random when asked to locate relevant information. Implementation of the intervention package did allow participants to complete worksheets similar to their general education peers and to use textbooks to find answers to questions on their worksheets. Their written class work was turned in to their teacher and scored as a portion of their class grade. In future research efforts should be made to investigate the effects of the intervention package on students' comprehension of the content of their textbooks as a result of using the strategies taught to comp lete modified worksheets.

Second, students in this study completed short-answer worksheets, as did their general education peers. Such seatwork may be a questionable use of instructional time, particularly for students with poor reading skills. However, we attempted to support participants in meeting the actual demands of the classroom in which they were enrolled, although some of the instructional methods used may not have been recommended practice (Choate \& Rakes, 1997). The skills addressed in this study were those identified as necessary for success within the parameters of that particular environment. Modifying classroom materials and teaching students strategies to complete assignments may be an effective first step in promoting successful inclusion in the general education curriculum (Janney \& Snell, 1997). In the future researchers should investigate applying similar strategies to other classroom performance behaviors, such as participating in cooperative group projects with general education peers.

Third, participants' involvement in goal setting in this study was limited. For example, participants were asked to determine performance goals related to a specific behavior (i.e., completing classroom assignments) rather than being asked to select broader goals related to a behavior that they chose to target. Future investigators should attempt to increase the involvement and decision-making of participants in setting goals that may have a greater impact on their everyday lives, such as choosing to pursue a specific career or planning where to live after high school.

Fourth, although the general education teacher collaborated in designing the modified worksheets, her role in implementation of the intervention was limited (e.g., she did not directly train participants). 
Her comments regarding the acceptability of intervention procedures, therefore, must be interpreted with caution. Preparing the modified worksheets and providing training in worksheet completion and self-monitoring was timeconsuming. Secondary teachers typically have great demands placed on their planning and preparation time. It may be unrealistic to expect them to devote considerable time to modifying instruction. Close collaboration between general and special education teachers may be one means to address this issue. Sharing the task of preparing appropriately modified classroom assignments may reduce the workload required to support students with mental retardation in the general education curricula.

Increasing participation in the general education curricula as mandated by the 1997 IDEA amendments requires developing strategies that support students' participation in the everyday demands of the general education classroom environment. General education teachers need to learn strategies they can use to support students with disabilities who are included in their classes. Results of the present study suggest that when students with mental retardation enrolled in general education classes receive multiple supports targeted for the demands of their particular classroom, they can improve their performance of expected classroom behaviors. Future investigators should address the effectiveness of having general education teachers themselves, rather than research staff, implement the student support strategies found to be effective in this study.

\section{References}

Choate, J. S., \& Rakes, T. A. (1997). Reading comprehension: Process, skills, and strategies. In J. S. Choate (Ed.), Successful inclusive teaching: Proven ways to detect and correct special needs (pp. 82-125). Boston: Allyn \& Bacon.

deBettencourt, L. U. (1999). General educators' attitudes toward students with mild disabilities and their use of instructional strategies: Implications for training. Remedial and Special Education, 20, 27-35.

deBettencourt, L. U., \& Allen, J. (1999). Programming for middle and high school: A studyskills clinic approach for preparing teachers. Teacher Educator, 35, 8-18.

Farlow, L. (1996). A quartet of success stories:
How to make inclusion work. Educational Leadership, 53, 51-55.

Foley, R. M., \& Epstein, M. H. (1993). A structured instructional system for developing the school survival skills of adolescents with behavioral disorders. Behavioral Disorders, 18 , 139-147.

German, S. L., Martin, J. E., Marshall, L. H., \& Sale, R. P. (2000). Promoting selfdetermination: Using Take Action to teach goal attainment. Career Development for Exceptional Individuals, 23, 27-38.

G'rossi, T. A., \& Heward, W. L. (1998). Using selfevaluation to improve the work productivity of trainees in a community-based restaurant training program. Education and Training in Mental Retardation and Developmental Disabilities, 33, 248-263.

Hamre-Nietupski, S., Dvorsky, S., McKee, A., Nietupski, J., Cook, J., \& Costanza, C. (1999). Going home: General and special education teachers' perspectives as students with moderate/severe disabilities return to rural neighborhood schools. Education and Training in Mental Retardation and Developmental Disabilities, 34, 235-259.

Hunt, P., Alwell, M., ' Goetz, L., \& Sailor, W. (1990). Generalized effects of conversation skill training. Journal of the Association for Persons with Severe Handicaps, 15, 250-260.

Individuals With Disabilities Education Act Amendments of 1997, Pub. L. 105-17, 20 U.S.C. 1400 et seq. (1997).

Janney, R., \& Snell, M. E. (1997). How teachers include students with moderate and severe disabilities in elementary classes: The means and meaning of inclusion. Journal of the Association for Persons with Severe Handicaps, 22, 159-169.

Janney, R., \& Snell, M. E. (2000). Teachers' guides to inclusive practices: Modifying schoolwork. Baltimore: Brookes.

Kazdin, A. E. (1982). Single case research design: Methods for clinical and applied settings. New York: Oxford University Press.

Kokubun, M. (1999). The relationship between the effect of setting a goal on standing broad jump performance and behaviour regulation ability in children with intellectual disability. Journal of Intellectual Disability Research, 43, 1318.

MacArthur, C. A., Schwartz, S. S., Graham, S., Molloy, D., \& Harris, K. (1996). Integration 
of strategy instruction into a whole language classroom: A case study. Learning Disabilities Research C'Practice, 11, 168-176.

McDonnell, J. (1998). Instruction for students with severe disabilities in general education settings. Education and Training in Mental Retardation and Developmental Disabilities, 33, 199-215.

Monda-Amaya, L. E., Kieker, L., \& Reed, F. (1998). Preparing students with learning disabilities to participate in inclusive classrooms. Learning Disabilities Research \& Practice, 13, 171-182.

Polloway, E. A., Patton, J. R., Smith, T. E. C., \& Buck, G. H. (1997). Mental retardation and learning disabilities: Conceptual and applied issues. Journal of Learning Disabilities, 30, 297308, 345.

Smith, D. J., \& Nelson, R. J. (1997). Goal setting, selfmonitoring, and self-evaluation for students with disabilities. In M. Agran (Ed.), Student directed learning: Teaching self-determination skills (pp. 80110). Pacific Grove, CA: Brooks/Cole.

Snyder, M.,, C.,._\&..Bambara, L. M.,(1997). Teaching secondary students with learning disabilities to 'selfmanage classroom survival skills. Journal of Learning Disabilities, 30, 534-543.

Tralli, R., Colombo, B., Deshler, D. D., \& Schumaker, J. B. (1996). The strategies intervention model: A model for supported inclusion at the secondary level. Remedial and Special Education, 17, 204-216.
Trammel, D. L., Schloss, P. J., \& Alper, S. (1994). Using self-recording, evaluation, and graphing to increase completion of homework assignments. Journal of Learning Disabilities, 27, 7581.

Wehmeyer, M. L., Agran, M., \& Hughes, C. (1998). Teaching self-determination to students with disabilities: Basic skills for successful transition. Baltimore: Brookes.

Vallecorsa, A., \& deBettencourt, L. U. (1997). Using a mapping procedure to teach reading and writing skills to middle grade students with learning disabilities. ,Education and Treatment of Children, 20, 173-188.

Received 7/31/00, accepted 3/27/01.

This study was supported in part by Grant H023D990001 from the Office of Special Education and Rehabilitative Services, U. S. Department of Education, the John F. Kennedy Center for Research on Human Development at Vanderbilt University, and a grant from the John Merck Foundation. We thank the students and teachers at Pearl Cohn High School, Nashville, Tennessee. The research is based on a dissertation submitted by the first author to the Department of Special Education, Vanderbilt University, in partial fulfillment of the requirements for the doctoral degree. Requests for reprints should be sent to Susan R. Copeland, College of Education, Special Education, University of New Mexico, Albuquerque, NM 87131-1231. E-mail: susanrc@unm.edu. 